\title{
HUBUNGAN ANTARA SENAM HAMIL DENGAN LAMANYA PROSES PERSALINAN PADA PRIMIPARA DI PUSKESMAS SEGIRI SAMARINDA
}

\author{
${ }^{1}$ Puji Handayani, ${ }^{2}$ Siti Aminah, ${ }^{3}$ Wiwik Herawati, ${ }^{4}$ Endang Iriani \\ ${ }^{1}$ Bidan RSU Islam Samarinda \\ ${ }^{2}$ Bidan Puskesmas Remaja Samarinda \\ ${ }^{3}$ Bidan Puskesmas Segiri Samarinda \\ ${ }^{4}$ Bidan Puskesmas Sempaja Samarinda
}

\begin{abstract}
Abstrak
Senam hamil merupakan cara yang mendukung kemudahan dalam persalinan. Senam hamil bertujuan mempersiapkan dan melatih otot-otot sehingga dapat berfungsi secara optimal dalam persalinan normal. Senam hamil ditujukan bagi ibu hamil tanpa kelainan atau tidak terdapat penyakit yang disertai kehamilan, yaitu penyakit jantung, penyakit ginjal, penyulit kehamilan (hamil dengan perdarahan, hamil dengan kelainan letak), dan kehamilan disertai anemia. Rumusan masalah dalam penelitian ini adalah "Apakah ada Hubungan antara senam hamil dengan lamanya proses persalinan pada primipara di Puskesmas Segiri?". Penelitian ini bertujuan untuk mengetahui Hubungan antara senam hamil dengan lamanya proses persalinan pada Primipara.Populasi dalam penelitian ini adalah ibu primipara yang pernah melakukan senam hamil dan telah mengalami proses persalinan. Sampel dalam penelitian ini menggunakan tekhnik Total Sampling. Hasil analisa menggunakan uji statistik Uji "Chi Square", dengan tingkat penerimaan $\mathrm{p}<0,05$, didapat hasil $\alpha=$ 0,001 dan nilai $X^{2}$ hitung $=14,742$ dan $X^{2}$ tabel 3,815 artinya H0 ditolak sehingga dapat disimpulkan terdapat hubungan yang bermakna antara senam kehamilan dengan lama persalinan ibu primipara di kelurahan Teluk Lerong ulu.
\end{abstract}

Kata Kunci: Ibu primipara, senam hamil, lama persalinan

\begin{abstract}
The relationship between theduration of process Gymnastics Pregnant Maternity Mother primiparousin the Villageat Bay Lerong Samarinda Ulu. Pregnancy exerciseis away that supports the ease of child birth. Pregnancy exercise aims to prepareand train the musclesso it canfunction optimally in anormal delivery. Pregnancy exercise aimed at pregnant women with no abnormalities or there is no disease that accompanied pregnancy, heart disease, kidney disease, complications of pregnancy (pregnant with bleeding, pregnant with the location of abnormality), and pregnancy with anemia. Formulation of the problemin this study is "Is there a relationship between pregnancy exercise with duration of labor in primi parasat Samarinda. The research purpose to know the relationship between pregnancy exercise with duration of labor in primiparas Samarinda. The population in this study were primiparous women who never do gymnastics has under gone a process of pregnancy and child birth. The sample in this study uses Total Sampling techniques. Results of analysis using statistical tests "Chi Square", with the level of acceptance of $p<=0.001$ and calculate the $\alpha=0.05$, we got the result value of $X^{2}=14.742$ and $3.815 X^{2}$ tabel mean $\mathrm{H} 0$ rejected so that it can be concluded there is a significant association between gymnastics pregnancies with long delivery primiparous mothers in the village Gulf Lerong ulu.
\end{abstract}

Keywords: primiparous mother, pregnancy exercise, long delivery 


\section{PENDAHULUAN}

Mortalitas dan morbiditas pada wanita hamil dan bersalin adalah masalah besar di negara berkembang. Ini berarti kemampuan untuk memberikan pelayanan kesehatan masih memerlukan perbaikan kesehatan yang bersifat menyeluruh dan lebih bermutu. Dari hasil Survei Demografi Kesehatan Indonesia tahun 2007 Angka Kematian Ibu (AKI) di Indonesia sebesar 228 per 100.000 kelahiran hidup. AKI merupakan salah satu indikator untuk melihat derajat kesehatan perempuan. Angka kematian ibu juga merupakan salah satu target yang telah ditentukan dalam tujuan pembangunan Millenium Development Goals (MDGs) tujuan ke-5 yaitu meningkatkan kesehatan ibu dimana target yang dicapai pada tahun 2015 adalah mengurangi sampai $3 / 4$ resiko jumlah kematian ibu yaitu menjadi 118 per 100.000 kelahiran hidup. Telah terjadi penurunan yang sangat signifikan tetapi masih perlu upaya yang keras untuk mencapai target 2015 (SDKI, 2007).

Kalimantan Timur merupakan wilayah yang berstatus provinsi di Indonesia dengan luas wilayah $245.237,80 \mathrm{~km}^{2}$ yang terdiri dari 10 Kabupaten dan 4 Kota (Wikipedia, 2017). AKI di Kalimantan Timur juga semakin menurun, yakni dari 302/100.000 kelahiran hidup pada tahun 2004 menjadi 110/100.000 kelahiran hidup di tahun 2009 (ArsipBerita.com, 2017). Khusus untuk kota Samarinda sendiri ada 16.447 ibu hamil dalam satu tahun nya dengan jumlah yang beresiko sebanyak 3.289 ibu hamil. Serta tercatat jumlah kematian ibu sebanyak 6 jiwa, 3 karena perdarahan, 1 karena hipertensi dalam kehamilan, dan 1 karena infeksi (Dinkes Provinsi Kaltim, 2010).

Selama kehamilan, ibu mengalami perubahan fisik dan kejiwaan/emosi ibu hamil. Pada masa kehamilan, emosi mudah turun dan naik, yang terjadi akibat perubahan hormon. Adapun kecemasan menjelang pesalinan ibu hamil akan muncul. Pernyataan dan bayangan apakah dapat melahirkan normal, cara mengejan, apakah akan terjadi sesuatu saat melahirkan, atau apakah bayi lahir selamat, akan semakin muncul dalam benak ibu. Kondisi ini dapat menyebabkan kecemasan dan ketegangan lebih lanjut sehingga membentuk suatu siklus umpan balik yang dapat meningkatkan intensitas emosional secara keseluruhan. Untuk memutuskan siklus kecemasan tersebut, maka senam hamil sebagai salah satu pelayanan prenatal, merupakan suatu alternatif terapi yang dapat diberikan pada ibu hamil (Muhimah dan Safi'i, 2010).

Senam hamil merupakan cara yang mendukung kemudahan dalam persalinan. Senam hamil bertujuan mempersiapkan dan melatih otot-otot sehingga dapat berfungsi secara optimal dalam persalinan normal. Senam hamil ditujukan bagi ibu hamil tanpa kelainan atau tidak terdapat penyakit yang disertai kehamilan, yaitu penyakit jantung, penyakit ginjal, penyulit kehamilan (hamil dengan perdarahan, hamil dengan kelainan letak), dan kehamilan disertai anemia. Senam hamil dapat mengurangi berbagai gangguan yang umumnya terjadi selama kehamilan seperti varises, sakit pinggang serta nyeri otot dan persendian, meningkatkan stamina yang sangat diperlukan selama persalinan dan menguatkan serta mengencangkan otot yang paling banyak mempengaruhi dalam kehamilan yaitu otot pelvis, otot perut, dan otot pinggang (Hanton, 2001).

Hasil penelitian tahun 2000 yang dimuat dalam American Journal of Obstetrics and Gynecology menunjukkan bahwa ibu-ibu yang melakukan senam hamil yang cukup, sering dan teratur selama tiga bulan terakhir mengalami persalinan yang tidak begitu sakit dibandingkan dengan persalinan para ibu yang tidak melakukan senam hamil (Hanton, 2001). Senam hamil dapat diambil manfaatnya pula pada perawatan tubuh dan citra diri agar tetap cantik dan bugar serta 
mengurangi timbulnya berbagai gangguan akibat perubahan postur tubuh. Latihan senam hamil tidak dapat dikatakan sempurna bila penyajiannya tidak disusun secara teratur yaitu tiga kali dalam seminggu yang dimulai dari usia kehamilan 22 minggu sampai menjelang kelahiran (Irmayanti, 2007).

Pergerakan dan latihan senam kehamilan tidak saja menguntungkan sang ibu, tetapi juga sangat berpengaruh terhadap kesehatan bayi yang di kandungan. Pada saat bayi mulai dapat bernafas sendiri, maka oksigen akan mengalir kepadanya melalui plasenta, yaitu dari aliran darah ibunya ke dalam aliran darah bayi yang di kandung. Senam kehamilan akan menambah jumlah oksigen dalam darah di seluruh tubuh sang ibu dank arena itu aliran oksigen kepada bayi melalui plasenta juga akan menjadi lebih lancar (Hanton, 2001).

Berdasarkan hasil study pendahuluan yang dilakukan melalui wawancara di peroleh data dari 15 responden di dapatkan sebanyak 9 ibu primipara yang mengikuti senam hamil mengalami proses persalinan normal, dengan lama persalinan 60 menit, dan tidak mengalami nyeri yang hebat serta dapat mengatur pernapasan pada saat kontraksi dan sebanyak 6 ibu primipara tidak melakukan senam hamil dengan proses persalinan normal dengan lamanya persalinan 90 menit serta mengalami kesulitan pada saat proses persalinan.

Berdasarkan latar belakang di atas penulis tertarik untuk meneliti "Apakah Ada Hubungan antara senam hamil dengan lamanya proses persalinan pada primipara di Puskesmas Segiri Samarinda Samarinda?"

\section{Rumusan Masalah}

Berdasarkan latar belakang tersebut diatas, maka perumusan masalah dalam penelitian ini adalah "Apakah ada Hubungan antara senam hamil dengan lamanya proses persalinan pada primipara di Puskesmas Segiri Samarinda Samarinda"

\section{METODE PENELITIAN}

Dalam penelitian ini penulis menggunakan jenis penelitian analitik. Metode analitik adalah penelitian yang melakukan analisis dinamika korelasi antara fenomena atau antara faktor resiko dengan efek.

Penelitian ini akan dilaksanakan pada bulan Mei 2017. Lokasi penelitian akan dilaksanakan di Puskesmas Segiri yang telah melakukan senam hamil dan telah mengalami proses persalinan.

Pada penelitian ini metode yang digunakan adalah Total sampling yaitu menurut Arikunto, bila populasi kurang dari 100 orang, maka diambil keseluruhan. Berdasarkan pernyataan ini, karena populasi kurang dari 100 orang, maka yang menjadi sampel dalam penelitian ini adalah seluruh populasi (100\%) yaitu 48 ibu primipara yang melakukan senam hamil dan telah mengalami proses persalinan.

Alat bantu yang digunakan dalam penelitian ini adalah berupa kuesioner (angket) dengan 4 pertanyaan dengan bentuk pertanyaan tertutup, yaitu responden tinggal memilih jawaban diantara pilihan yang sudah disediakan.

Uji validitas dalam penelitian menggunakan program SPSS dengan Korelasi Product Moment Person. Tehnik pengukuran reliabilitas internal menggunakan rumus alpha cronbach. Analisis univariat bertujuan untuk menjelaskan atau mendeskripsikan karakteristik setiap variable penelitian, baik variable terikat maupun variable bebas. Pada data kategorik peringkasan data hanya menggunakan distribusi frekuensi dengan aturan presentasi dengan rumus. (arikunto, 2002).

Uji statistik yang digunakan dalam penelitian ini adalah uji statistik Kai Kuadrat (Chi Square). Karena dalam penelitian tersebut peneliti melakukan analisis bivariat yaitu pengaruh variabel katagorik dengan variabel katagorik. 


\section{HASIL PENELITIAN}

Karakteristik responden dapat di uraikan sebagai berikut :

a. Umur

Tabel 1 : Distribusi Frekuensi

Responden berdasarkan Umur

\begin{tabular}{ccc}
\hline Umur & Frekuensi & $\mathbf{( \% )}$ \\
\hline$<20$ & 4 & $8,33 \%$ \\
$20-35$ & 43 & $89,58 \%$ \\
$>35$ & 1 & $2,09 \%$ \\
\hline Jumlah & $\mathbf{4 8}$ & $\mathbf{1 0 0} \%$
\end{tabular}

Sumber data : Data Primer (Juli, 2017)

Dari tabel 1 di atas dapat dilihat bahwa dari 48 responden, sebagian besar ibu primipara berusia 20-35 tahun sebanyak 43 orang $(89,58 \%)$ dan sebagian kecil berusia >35 Tahun sebanyak 1 orang $(2,09 \%)$.

\section{b. Pekerjaan}

Tabel 2 : Distribusi Frekuensi Responden berdasarkan Pekerjaan

\begin{tabular}{ccc}
\hline Pekerjaan & Frekuensi & $\mathbf{( \% )}$ \\
\hline IRT & 42 & $87,5 \%$ \\
PNS & 2 & $4,17 \%$ \\
SWASTA & 4 & $8,33 \%$ \\
\hline Jumlah & $\mathbf{4 8}$ & $\mathbf{1 0 0} \%$
\end{tabular}

Sumber data : Data Primer (Juli, 2017)

Dari tabel 2 di atas dapat dilihat bahwa dari 48 responden sebagian besar ibu responden bekerja sebagai ibu rumah tangga ada sebanyak 42 orang $(87,5 \%)$ dan sebagian kecil bekerja sebagai PNS sebanyak 2 orang $(4,17 \%)$.

c. Pendidikan

Tabel 3 : Distribusi Frekuensi Responden berdasarkan Pendidikan

\begin{tabular}{ccc}
\hline Pendidikan & Frekuensi & $\mathbf{( \% )}$ \\
\hline SD & 9 & $18,75 \%$ \\
SMP & 19 & $39,58 \%$ \\
SMA & 15 & $31,25 \%$ \\
D3 & 2 & $4,17 \%$ \\
S1 & 3 & $6,25 \%$ \\
\hline Jumlah & $\mathbf{4 8}$ & $\mathbf{1 0 0} \%$
\end{tabular}

Sumber data : Data Primer (Juli, 2017)

Dari tabel 3 di atas dapat dilihat bahwa dari 48 responden sebagian besar tingkat pendidikan ibu responden adalah pendidikan SMP sebanyak 19 orang $(39,58 \%)$, dan sebagian kecil tingkat pendidikan ibu responden adalah pendidikan D3 sebanyak 2 orang $(4,17 \%)$.

d. Agama

Tabel 4 Distribusi Frekuensi Responden berdasarkan Agama

\begin{tabular}{ccc}
\hline Agama & Frekuensi & $\mathbf{( \% )}$ \\
\hline Islam & 44 & $91,67 \%$ \\
Kristen & 4 & $8,33 \%$ \\
Hindu & 0 & $0,00 \%$ \\
Budha & 0 & $0,00 \%$ \\
\hline Jumlah & $\mathbf{4 8}$ & $\mathbf{1 0 0} \%$ \\
\hline \multicolumn{2}{l}{ Sumber data : Data Primer (Juli, }
\end{tabular}

2017)

Dari table4 di atas dapat dilihat bahwa dari 48 responden sebagian besar ibu Agama yang dianut ibu Responden ada $44(91,67 \%)$ siswa yang beragama Islam, $4(8,33 \%)$ siswa yang beragama kristen, dan tidak ada responden yang beragama Hindu dan Budha.

e. Sumber Informasi

Tabel 5 : Distribusi Frekuensi Responden berdasarkan Sumber Informasi

\begin{tabular}{ccc}
\hline $\begin{array}{c}\text { Sumber } \\
\text { Informasi }\end{array}$ & Frekuensi & $\mathbf{( \% )}$ \\
\hline Keluarga/Tetangga & 19 & $39,58 \%$ \\
Nakes & 25 & $52,07 \%$ \\
Internet & 1 & $2,09 \%$ \\
Media Cetak & 2 & $4,17 \%$ \\
Televisi & 1 & $2,09 \%$ \\
\hline Jumlah & $\mathbf{4 8}$ & $\mathbf{1 0 0} \%$ \\
\hline
\end{tabular}

Sumber data : Data Primer (Juli, 2017)

Karakteristik responden berdasarkan sumber informasi pada ibu Primipara diketahui bahwa sebagian besar berasal dari tenaga kesehatan 25 orang $(52,07 \%)$ dan sebagian kecil dari media internet dan media televis masing-masing sebanyak 1 orang $(2,09 \%)$. 


\section{Analisis Univariat}

\section{Senam Kehamilan}

Tabel 6 : Distribusi Frekuensi

Responden berdasarkan senam hamil padaibu primipara yang pernah melakukan senam hamildiPuskesmas Segiri

\begin{tabular}{|c|c|c|c|}
\hline No. & $\begin{array}{l}\text { Senam } \\
\text { Hamil }\end{array}$ & $\mathbf{F}$ & $\%$ \\
\hline $\begin{array}{l}1 \\
2\end{array}$ & $\begin{array}{l}\text { Sering } \\
\text { Jarang }\end{array}$ & $\begin{array}{l}37 \\
11\end{array}$ & $\begin{array}{l}77,10 \\
22,90\end{array}$ \\
\hline & Total & 48 & 100.00 \\
\hline
\end{tabular}

Sumber data : Data Primer (Juli, 2017)

Dilihat dari tabel 6 diatas menggambarkan ibu primipara yang pernah melakukan senam hamil dan telah mengalami proses persalinandi Kelurahan Teluk Lerongulu yaitu sebanyak 37 orang $(77,1 \%)$ ibu primipara sering mengikuti senam hamil dan sisanya 11 orang $(22,9 \%)$ jarang mengikuti senam hamil.

2. Lama Persalinan

Tabel7 : Distribusi $\quad$ Frekuensi Responden Berdasarkan lama proses persalinan pada ibu primipara yang pernah melakukan senam hamil di Puskesmas Segiri

\begin{tabular}{|c|c|c|c|}
\hline No. & $\begin{array}{c}\text { Lama } \\
\text { Persalinan }\end{array}$ & $\mathbf{F}$ & $\%$ \\
\hline $\begin{array}{l}1 \\
2\end{array}$ & $\begin{array}{l}\text { Tidak normal } \\
\text { Normal }\end{array}$ & $\begin{array}{c}8 \\
40\end{array}$ & $\begin{array}{l}16,7 \\
83,3\end{array}$ \\
\hline & Total & 48 & 100.0 \\
\hline
\end{tabular}

Sumber data : Data Primer (Juli, 2017)

Dilihat dari tabel 7 diatas menggambarkan tentanglama persalinan pada ibu primipara yang pernah melakukan senam hamil di Puskesmas Segiri yaitu sebanyak 40 orang $(83,3 \%)$ ibu primipara melakukan persalinan dengan normal dan sisanya 8 orang $(16,7 \%)$ ibu primipara melakukan persalinan dengan tidak normal.

\section{A. Analisa Bivariat}

Hubungan antara senam hamil dengan lama persalinan pada ibu primipara yang pernah melakukan senam hamil di Puskesmas Segiri dapat dianalisa dengan menggunakan Cross tabulation dan untuk mengetahui sifat hubungan tersebut dapat digunakan Uji Statistic Chi-Square (Pearson Chi-Square) dengan tingkat kemaknaan $\alpha=0,05$.

Tabel 8 : Statistik Deskriptif Hubungan antara senam hamil dengan lamanya proses persalinan pada ibu primipara yang pernah melakukan senam hamil di Puskesmas Segiri

\begin{tabular}{|c|c|c|c|c|c|c|c|}
\hline \multirow{4}{*}{$\begin{array}{l}\text { Senam } \\
\text { Hamil }\end{array}$} & \multicolumn{5}{|c|}{ Lama Proses Persalinan } & \multirow{4}{*}{$\begin{array}{l}p v \\
a l \\
u e\end{array}$} & \multirow{4}{*}{$\begin{array}{c}\text { Od } \\
\text { Rati } \\
\text { o }\end{array}$} \\
\hline & \multicolumn{2}{|c|}{ Tidak Normal } & \multicolumn{2}{|c|}{ Normal } & \multirow[t]{3}{*}{ Total } & & \\
\hline & $\mathbf{N}$ & $\%$ & $\mathbf{N}$ & $\%$ & & & \\
\hline & & & & & & & \\
\hline Jarang & 6 & $12.5 \%$ & 5 & $10,4 \%$ & $22,90 \%$ & & \\
\hline \multirow[t]{2}{*}{ Sering } & 2 & $4.2 \%$ & 35 & $72,9 \%$ & $77,10 \%$ & 0.0 & \\
\hline & & & & & & 01 & 21.00 \\
\hline
\end{tabular}

Sumber data : Data Primer (Juli, 2017)

Tabel 8 menjelaskan bahwa ibu primipara yang jarang mengikuti senam hamil dan lama persalinan tidak normal sebanyak 6 orang $(12,5 \%)$ dan yang lama persalinannya normal sebanyak 5 orang $(10,4 \%)$ sehingga ibu yang jarang mengikuti senam hamil ada sebanyak 11 orang $(22,90 \%)$, sementara ibu primipara yang sering mengikuti senam hamil dan lama proses persalinan tidak normal ada 2 orang $(4,2 \%)$ sementara ibu primipara yang sering mengikuti senam hamil dan lama persalinan normal sebanyak 35 orang $(72,9 \%)$ sehingga ibu yang sering mengikuti senam hamil ada sebanyak 37 orang $(77,10 \%)$ 
Untuk mengetahui hubungan variabel independen yaitu senam kehamilan terhadap variabel lama persalinan dilakukan dengan menggunakan uji Chi- Square dengan taraf signifikansi 5\%. Uji ini digunakan untuk mengadakan pendekatan dari beberapa faktor atau mengevaluasi frekuensi yang diteliti atau frekuensi hasil observasi (fo) dengan frekuensi yang diharapkan (fe) dari sampel apakah terdapat hubungan yang kuat atau tidak. Uji $\mathrm{X}^{2}$ digunakan pada data kategorik yang berskala ordinal (AgusRiyanto, 2009).

Hasil perhitungan chi-square dapat disimpulkan bahwa Ho ditolak artinya ada hubungan antara senam hamil dengan lamanya proses persalinan pada ibu primipara yang pernah melakukan senam hamil di Puskesmas Segiri.

Hasil uji ini juga didukung oleh hasil tabulasi silang antara senam hamildan lama proses persalinan dimana ada peningkatan jumlah responden yang mengalami lama persalinan tidak normal menjadi normal ketika ibu primipara sering mengikuti senam hamil yaitu sebanyak 4 responden. Dengan hasil OR yang 21,000 yang artinya ada 21 kali kemungkinan lama proses persalinan ibu primipara menjadi tidak normal ketika ibu primipara jarang mengikuti senam hamil.

Dari uji statistik "Uji Chi Square", dengan tingkat penerimaan $\mathrm{p}<0,05$, didapat hasil $\alpha=0,001$ dan nilai $\mathrm{X}^{2}$ hitung $=14,742$ dan $X^{2}$ tabel $=3,815$ artinya H0 ditolak sehingga dapat disimpulkan terdapat hubungan yang bermakna antara senam hamil dengan lamanya proses persalinan pada ibu primipara di Puskesmas Segiri.

\section{PEMBAHASAN}

1. Karaktersitik Responden
a. Karakteristik Responden berdasarkan umur

Dari hasil penelitian diketahui bahwa sebagian besar ibu primipara yang pernah melakukan senam hamil dan telah mengalami proses persalinan di Puskesmas Segiri berusia 20-35 tahun sebanyak 43 orang $(89,58 \%)$, usia kurang dari 20 tahun sebanyak 4 orang $(8,33 \%)$ dan hanya 1 orang $(2,09 \%)$ yang berusia lebih dari 35 tahun.

Usia mempengaruhi terhadap daya tangkap dan pola pikir seseorang. Semakin bertambah usia akan semakin berkembang pula daya tangkap dan pola pikirnya, sehingga pengetahuan yang diperolehnya akan semakin membaik, namun dalam perkembangan selama hidup bahwa semakin semakin tua umur seseorang maka akan berpengaruh pada IQ seseorang dan semakin banyak pengalamannya. (Notoatmojo, 2007).

\section{b. Karakteristik Responden}

\section{berdasarkan pekerjaan}

Dari hasil penelitian, sebagian besar ibu responden bekerja sebagai IRT sebanyak 42 orang $(87,5 \%), 4$ orang $(8,33 \%)$ dengan pekerjaan swasta serta ada 2 orang $(4,17 \%)$ yang bekerja sebagai PNS.

Maka dapat disimpulkan bahwa responden yang kesehariannya tidak disibukkan oleh pekerjaan mempunyai waktu yang lebih banyak untuk mendapatkan informasi tentang kesehatan baik melalui majalah, koran, TV, tenaga kesehatan, dari orang lain dan sebagainya atau mengikuti penyuluhan 
c. Karakteristik Responden
berdasarkan pendidikan
Dari hasil penelitian diketahui bahwa pendidikan ibu responden sebagian besar adalah pendidikan SMP sebanyak 19 orang $(39,58 \%)$, SMA sebanyak 15 orang $(31,25 \%)$, SD sebanyak 9 orang $(18,75 \%), \mathrm{S} 1$ sebanyak 3 orang $(6,25 \%)$ dan D3 sebanyak 2 orang $(4,17 \%)$.

Pendidikan adalah suatu usaha untuk mengembangkan kepribadian dan kemampuan di dalam dan di luar sekolah atau perguruan tinggi dan berlangsung seumur hidup. Tingkat pendidikan akan mempengaruhi daya serap responden terhadap informasi yang diterima. Dengan pendidikan yang cukup tinggi terjadi proses pertumbuhan, perkembangan atau perubahan ke arah yang lebih baik dan matang pada diri individu (Notoatmodjo, 2003) sehingga responden akan mudah menerima pengaruh dari luar, lebih objektif dan terbuka terhadap berbagai informasi termasuk informasi kesehatan.

Pada penelitian ini dapat disimpulkan bahwa pendidikan tertinggi ibu responden adalah pendidikan SMP yaitu sebanyak 19 orang $(39,58 \%)$. Hal ini juga menunjukan bahwa pendidikan merupakan dasar pengetahuan ibu primipara yang bisa didapat melalui pendidikan formal dan tidak formal serta dari orang lain, tenaga kesehatan atau media massa. Semakin tinggi pendidikan seseorang maka pengetahuannya akan semakin luas atau baik, selain itu semakin tinggi pendidikan seseorang akan mempermudah orang tersebut dalam menerima informasi.

\section{d. Karakteristik Responden berdasarkan Agama}

Dari hasil penelitian agama yang dianut ibu responden sebagian besar adalah Agama Islam sebanyak $(91,67 \%)$ dan sebagian kecil beragama kristen sebanyak $(8,33 \%)$.

\section{e. Karakteristik Responden berdasarkan Sumber Informasi}

Dari hasil penelitian diketahui bahwa sumber informasi yang didapat ibu primipara tentang senam hamil $52,07 \%$ atau sebanyak 25 orang bersumber dari Tenaga kesehatan, 39,58\% atau sebanyak 19 orang bersumber dari keluarga/tetangga, dan sisanya bersumber dari media cetak, internet dan media televisi.

Menurut Notoadmodjo (2005) Sumber informasi adalah sesuatu yang menjadi perantara dalam menyampaikan informasi, merangsang pikiran dan kemampuan, informasi yang diperoleh dalam menyampaikan informasi yang diperoleh dari berbagai sumber akan mempengaruhi tingkat pengetahuan seseorang. Bila seseorang memperoleh informasi, maka cenderung mempunyai pengetahuan yang lebih luas.

Pada penelitian ini disimpulkan bahwa ibu responden mendapatkan informasi tentang senam kehamilan lebih banyak diperoleh dari tenaga medis atau tenaga kesehatan yaitu $52,07 \%$ atau sebanyak 25 orang. Sumber informasi yang di dapat melalui konseling dari bidan atau tenaga kesehatan pada waktu pemeriksaan kehamilan.

\section{Senam Hamil}


Dari hasil penelitian dapat diketahui bahwa ibu primipara yang pernah melakukan senam hamil dan telah mengalami proses persalinan di Puskesmas Segiri yaitu sebanyak 37 orang $(77,1 \%)$ ibu primipara sering mengikuti senam hamil dan sisanya 11 orang $(22,9 \%)$ jarang mengikuti senam hamil.

Dari hasil data tersebut dapat disimpulkan bahwa lebih banyak ibu yang sering mengikuti senam hamil dari pada yang jarang mengikuti senam hamil yaitu sebanyak 37 orang $(77,1 \%)$. Hal itu dikarenakan ibu primipara di kawasan tersebut mengikuti anjuran dari bidan di puskesmas setempat untuk ikut bergabung melaksanakan senam hamil yg diadakan setiap 1 bulan sekali agar dapat menjalani proses persalinan secara normal.

Senam hamil adalah terapi latihan gerak yang diberikan kepada ibu hamil untuk mempersiapkan dirinya, baik persiapan fisik maupun mental untuk mengahadapi dan mempersiapkan persalinan yang cepat, aman dan spontan (Hanton, 2001 : 90).

\section{Lama Proses Persalinan}

Hasil penelitian menggambarkan tentang lama proses persalinan pada ibu primipara yang pernah melakukan senam hamil di Puskesmas Segiri yaitu sebanyak 40 orang $(83,3 \%)$ ibu primipara melakukan persalinan dengan normal dan sisanya 8 orang $(16,7 \%)$ ibu primipara melakukan persalinan dengan tidak normal.

Persalinan adalah proses di mana bayi, plasenta, selaput ketuban keluar dari uterus ibu. Persalinan dianggap normal jika prosesnya terjadi pada usia kehamilan cukup bulan (setelah kehamilan 37 minggu) tanpa disertai adanya penyulit. Helen Varney mengatakan persalinan adalah rangkaian proses yang berakhir dengan pengeluaran hasil konsepsi oleh ibu. Proses ini dimulai dengan kontraksi persalinan sejati, yang ditandai oleh perubahan progresif pada serviks, dan diakhiri dengan kelahiran plasenta (Varney,H, 2007).

Tahap persalinan dibagi dalam 4 kala, salah satunya ialah kala II. Kala II adalah kala pengeluaran janin dimulai dari pembukaan lengkap $(10 \mathrm{~cm})$ sampai bayi lahir, proses ini biasanya berlangsung $1,5 \quad-2$ jam pada primigravida dan 0,5 - 1 jam pada multigravida (Mochtar, 1998).

Dari penelitian yang dilakukan dapat disimpulkan bahwa lebih banyak ibu primipara yang melakukan persalinan dengan normal yaitu sebanyak 40 orang $(83,3 \%)$. Dengan sering melakukan senam hamil maka proses persalinan yang dialami ibu primipara adalah persalinan normal dengan lama persalinan 60-90 menit.

4. Hubungan senam hamil dengan lamanya proses persalinan

Dari uji statistik "Uji Chi Square", dengan tingkat penerimaan $\mathrm{p}<0,05$, didapat hasil $\alpha=0,001$ dan nilai $\mathrm{X}^{2}$ hitung $=14,742$ dan $X^{2}$ tabel $=3,815$ artinya H0 ditolak sehingga dapat disimpulkan terdapat hubungan yang bermakna antara senam hamil dengan lama proses persalinan ibu primipara di Puskesmas Segiri. Dengan hasil OR yang 21,000 yang artinya ada 21 kali kemungkinan lama persalinan ibu primipara menjadi tidak normal ketika ibu primipara jarang mengikuti senam hamil.

Helen Varney mengatakan persalinan adalah rangkaian proses yang berakhir dengan pengeluaran hasil konsepsi oleh ibu. Proses ini dimulai dengan kontraksi persalinan sejati, yang ditandai oleh perubahan progresif pada serviks, dan diakhiri dengan kelahiran plasenta (Varney,H, 2007 : 672). 
Sedangkan tahap persalinan dibagi dalam 4 kala, salah satunya ialah kala II. Kala II adalah kala pengeluaran janin dimulai dari pembukaan lengkap $(10 \mathrm{~cm}$ ) sampai bayi lahir, proses ini biasanya berlangsung $1,5-2$ jam pada primigravida dan $0,5-1$ jam pada multigravida (Mochtar, 1998).

Berdasarkan hasil analisa data penelitian dapat disimpulkan bahwa senam hamil mempunyai hubungan yang bermakna dengan lama proses persalinan dimana ada kesenjangan antara ibu yang sering melakukan senam hamil dan jarang melakukan senam hamil yang akan berpengaruh pada lamanya proses persalinan. Lamanya proses persalinan ibu primipara yang sering melakukan senam hamil membutuhkan waktu lebih singkat dan normal yakni selama 60-90 menit di bandingkan dengan ibu yang jarang melakukan senam hamil yang membutuhkan waktu lebih dari normal yakni > 90 menit.

\section{KESIMPULAN}

Berdasarkan penelitian pada ibu primipara di Puskesmas Segiri Samarinda diketahui bahwa :

Berdasarkan hasil uji statistik "Uji Chi Square", dengan tingkat penerimaan $\mathrm{p}<$ 0,05 , didapat hasil $\alpha=0,001$ dan nilai $\mathrm{X}^{2}$ hitung $=14,742$ dan $X^{2}$ tabel 3,815 artinya H0 ditolak sehingga dapat disimpulkan terdapat hubungan yang bermakna antara senam hamil dengan lama proses persalinan pada ibu primipara di Puskesmas Segiri. Hasil penelitian ini menjadi bahanm masukan sebagai panduan pelayanan ibnu hamil primipara terhadap pelayanan senam hamil persiapan untuk persalinan yang lancar.

\section{DAFTAR PUSTAKA}

Arikunto. 2006. Prosedur Penelitian Suatu Pendekatan Praktik. Jakarta : Rineka cipta.

Arief, T. 2008. Kesehatan ibu Hamil dan Ibu Melahirkan. Jakarta : EGC

Dep. Kes. Bud. RI. 2001. Kamus Besar Bahasa Indonesia. Jakarta : Balai Pustaka.

Hanton, TW. 2001. Panduan Senam Kebugaran Untuk Wanita Hamil. Jakarta : PT Raja Grafindo Persada.

Hidayah, A. 2007. Metode Penelitian Kebidanan Dan Teknik Analisis Data. Jakarta : Salemba Medika.

Irmayanti. 2007. Pengetahuan. Available on line : http :// www.Wikipedia.org / wiki /pengetahuan, Diakses tanggal 19 Maret 2011.

Mandriwati, G A. 2008. Penuntun Belajar Asuhan Ibu Hamil. Jakarta: EGC.

Mansjoer, A. DKK. 2001. Kapita Selekta

Kedokteran. Fakultas Kedokteran Universitas Indonesia : Media Aesculapius.

Maureen, B. 2005. Mempersiapkan Kelahiran Bayi Anda. Jakarta : EGC.

Mellyna, H. 2002. Panduan Menjalani Kehamilan Sehat. Jakarta : Puspa Swara.

Mochtar, R. 1998. Sinopsis Obstetri. Jakarta : EGC.

Muhimah, 2010. Мепијu Kelahiran Yang

Alami. Jakarta: PT. Raja Grafindo

Persada 
JURNAL KEBIDANAN MUTIARA MAHAKAM VOLUME VI, NOMOR 2, SEPTEMBER 2018

Notoadmojo, Soekidjo. 2002. Metodologi Penelitian Kesehatan. Jakarta : PT. Rineka Cipta. 